\title{
Analysis of Teaching Reform of Computer Application Based on Flipping Classroom \\ Lijuan Qin ${ }^{1,2, a}$ and Liyun Wang ${ }^{1,2, b}$
}

\author{
${ }^{1}$ School of Information Engineering, Zhengzhou University of Industrial Technology, Zhengzhou \\ Henan 451150,PR China \\ ${ }^{2}$ Machine learning and Data researching Institute, Zhengzhou University of Industrial Technology, \\ Zhengzhou Henan 451150,PR China \\ a 654259624@qq.com, ${ }^{\mathrm{b}} 912725921 @ q q . c o m$
}

Keywords: Flip classroom; Computer application fundamentals; Teaching reform

\begin{abstract}
Flipping the classroom is a new teaching mode advocated in the current era of network information. It overturns the traditional classroom teaching mode. It mainly allows students to get a general understanding of the knowledge and skills they learned through online "micro lessons" before class. Detailed entry and analysis are carried out to achieve the goal of improving students' practical ability. This article will use some of the school's computer application basic course as a case of using the flip classroom teaching mode, analyze the steps and precautions of flipping the classroom teaching mode, and understand the flipping classroom in teaching activities from practical application cases. Advantages, thereby promoting the reform of computer basic education in Chinese universities.
\end{abstract}

\section{Introduction}

The so-called "flipping classroom", also known as "inverted classroom" or "inverted classroom", the essence of which is to flip the traditional classroom teaching model, so that students in the class through video, courseware, material and other forms to complete the past classroom The knowledge that should be mastered, and then in-depth discussion and exchange with classmates and teachers in the classroom is a brand-new teaching model that promotes the absorption and transformation of classroom theoretical knowledge [1]. Applying the flipping classroom teaching model to the basic computer application teaching in current colleges and universities can help improve students' computer operation skills and comprehensive quality, ensure the quality and effectiveness of computer basic teaching work, and promote the reform and innovation of basic computer application teaching in colleges and universities.

\section{Current Status of Computer Application Basic Teaching}

The basic course of computer application is a computer course opened by college students after entering the school. The author combines many years of work experience to analyze the problems existing in current basic computer application teaching:

\section{Insufficient Class Hours}

Judging from the actual situation of curriculum setting in most major colleges and universities, computer application basic courses will generally be set up in the first semester of freshman year, but due to the late arrival time of freshmen, plus military training, this will result in serious lesson hours. Insufficiency, the quality of teaching cannot be guaranteed.

\section{Single Teaching Mode}

So far, most teachers still use the project-based case teaching method in the basic teaching of computer application. This kind of unitary teaching model is difficult to adapt to the development of the current era, and it is impossible to display the creativity of students.

\section{Cannot Balance Differences}

At present, the practical training of computer operations still uses the traditional form of 
face-to-face teaching. However, this type of teaching is difficult to exercise the cooperation ability among students, and it is difficult to take into account the individual differences in students' existence and cannot teach students in accordance with their aptitude. In addition, student students originate from all over the country, and many universities and colleges are specialized in arts and sciences, and the level of students' computers is quite different, which also makes it difficult for practical computer application basic teaching.

Through the above description of various problems, it can be clearly seen that the basic teaching of computer application in colleges and universities using the traditional teaching model is in urgent need of reform, and applying the flipping classroom teaching model to the basic course of computer application can effectively change this phenomenon.

\section{Flip Classroom Application Mode Application Process}

Although many scholars at home and abroad have different views on the definition of "flipping classroom", but from the actual situation of education in our country, the author believes that the so-called flip classroom teaching mode is to use the video of the micro-course on the Internet platform to allow students to spend more than the classroom teaching. Time to master the general knowledge of the knowledge and skills learned, and then in the course of class teaching will be puzzled and teachers face to face discussion, teachers can also carry out learning activities to improve students' knowledge transfer ability, and then allow students to master the knowledge learned More secure ${ }^{[2]}$. The flipping classroom effectively combines extra-curricular network teaching with classroom teacher teaching, complementing each other's advantages and making the efficiency of teaching work further improved. Starting from the students' psychological characteristics and student rules, the author believes that the overturned classroom teaching model should be based on the web platform. The specific application process can be divided into the following four aspects:

\section{Micro-learning Development}

The author believes that in the flipping classroom teaching mode, students' extracurricular video teaching should be carried out in the way of micro lessons. In the flipping classroom teaching mode, the medium for transferring knowledge mainly relies on the video in the network platform, and the time for the students to watch the video is concentrated outside class. If the video time is too long, it will easily make the students feel impatient and unable to concentrate. As a teaching video within ten minutes, micro-curriculum presents many points of knowledge in the video in a hierarchical manner. The compact rhythm can concentrate the attention of the students. Therefore, pre-school instructional videos appear in the form of micro lessons. In the process of micro-curriculum development, teachers must consider the actual situation and do three tasks:(1)Analysis session. Focuses on the development of major learning audiences, learning objectives, learning content, learning effects, and more.(2)Design process. Through the analysis of the required learning points, the teaching methods, links, and the help that students may need in the learning process are designed.(3)Development. After the basic design conception, the PPT courseware and the recording of the teaching videos of the micro-curriculum were made, and related resources were then uploaded to the online platform for students to study outside the classroom ${ }^{[3]}$. For the production software of the micro lesson video, I recommend ViewLetCam, and we must ensure that the video time of each class of micro lesson can not exceed 10 minutes, the important purpose is to clarify a certain knowledge point or problem.

\section{Self-study Before Class}

The students' self-study course before class can be independently completed by the students during the extracurricular time as long as they rely on the micro-course video and quizzes test in the online course platform. First of all, teachers should set clear learning tasks and play a guiding role. Through the requirements of the task, students should make clear the learning objectives of the lesson, and follow the teacher's recommended learning steps and related tasks to carefully watch the video of the micro lesson and then proceed with The accompanying quizzes test to deepen the understanding of knowledge points. In this process, students can choose their own learning 
resources and can pause at any time in the process of playing videos, recording doubts and notes encountered during the self-study process. You can ask online teachers questions in the learning space, or you can enter the chat room to discuss with other students. In the process of self-study before the students' class, the teacher can not completely ignore it, but should make full use of the back-end management of the website to understand the student's learning dynamics in real time, master the students' online learning situation, the statistics of the supporting test scores, and solve the problems raised by the students. To find the common ground of the questions raised by the students, so as to formulate a good classroom teaching plan, and focus on the difficult points in the classroom teaching process.

\section{Classroom Promotion}

Through self-study by watching the video of the lesson before class, students have a basic understanding of the basic theoretical knowledge involved in the classroom teaching. The teacher designs the classroom teaching activities by focusing on the key issues raised during the student's self-learning process, and intensifies this part of the knowledge. The development, innovation, and sublimation will focus on how to improve students' ability to solve practical problems. In the process of designing and actually implementing classroom teaching activities, teachers can adopt groupings to allow students to discuss the learning tasks left by teachers in pre-school self-study, put forward their own opinions on the issues, and then report through various groups., Students' results are fully communicated.

\section{Summary Evaluation}

The student submits the completion of the teaching task to the teacher. The teacher makes a comprehensive comment and summarizes the completion of the student's learning task and evaluates the student's performance in the learning process. The summary evaluation content is not only a summary of the knowledge points learned, but also a summary evaluation of students' learning behavior performance and results. By effectively summarizing the assessment, students can face up to their own learning methods and behaviors in the flipping classroom teaching model, and get reflection and promotion from them.

\section{The Practical Application of Flipping Classroom Teaching Mode In Computer Application Basic Teaching}

Learning topics: "Word Processing and Editing - Word2010 Software Operation" in the "Basics of Computer Application for College Students" section of "Introducing Products with Word 2010".

Micro-learning development: The teacher can categorize the knowledge points of this section carefully and break it down: font settings, paragraph settings, column settings, artistic font insertion and formatting, text box drawing and formatting, picture insertion And format settings, shape insertion and formatting, page header and footer insertion, and page setup, etc., then record a micro-chronological video with a tight rhythm for these knowledge points and upload it to the corresponding computer application basic classification in the college's online classroom platform. Teaching column.

Self-study before class: Students follow the self-study task given by the teacher to watch the corresponding micro-teaching video, and download the teaching materials involved in the video from the online platform, and complete the video tutorial and teaching material application of the micro-teaching. Teacher's set task - "Product Description." While watching the video of the micro lesson and self-financing teaching tasks, students can communicate their doubts in the chat room with their classmates, or they can ask questions to the online teacher, thus earnestly completing the corresponding classroom tests and teacher assignments. . The students learn the whole process of the course, including the time spent and the test situation. The teachers can view it in the background management platform, and then have a general understanding of the students' knowledge of the knowledge.

Classroom promotion: Teachers can allow students to exchange groups in the classroom, and answer each other's questions in classroom self-study. Then each group reports on pre-class self-study and problems that are difficult for everyone to solve. When teachers apply Word 2010 to 
students After the puzzles are solved, teachers can guide students to revisit the layout in the "Product Description" in the textbook, add their own design ideas, and use the Word 2010 editing knowledge to make the layout more beautiful. personalise. In the traditional teaching classroom in the past, teachers only required students to complete the "Production Product Introduction" typesetting set in the textbook, which means that the purpose of teaching is achieved. There is no further in-depth revision and personalized creation. This is also the flipping of the classroom teaching model. Improve the effectiveness of classroom teaching. In the course of personalization design, students give full play to personal creativity, and in the process of design, they further consolidate the application capabilities of various tools of Word2010 software, and in the process of application, they can get timely guidance from teachers and allow students to Computer application capabilities and innovation capabilities have been jointly improved, which has greatly improved the quality and efficiency of classroom teaching.

Summarizing and evaluating: presenting the students' self-creating personalized "production product introduction", summarizing the computer theory knowledge and basic operations involved, and making an overall evaluation of the students' performance in the classroom and the completion of the tasks, and finally selecting Teachers and students agree that the most innovative "Product Description" works.

\section{Conclusion}

In summary, with the rapid development of information technology, flipping the classroom teaching model also has a certain impact on the traditional teaching model. The application of flipping classroom teaching in the basic teaching of computer application in colleges and universities redistributes the time and focus of study inside and outside the classroom of the students, making the basic application of computer application more efficient and compact, and effectively improving students' learning process. The enthusiasm and autonomy fully embody the student's dominant position in the learning process, and to a certain extent, the students' self-learning ability, question feedback ability, and practical application ability of computer knowledge are exercised. Practice shows that the flipping classroom teaching model is practical and feasible in the teaching of basic computer application in colleges and universities. The relevant educators should deeply study the connotation of the flipping classroom teaching model and promote the reform and innovation of computer application basic teaching.

\section{References}

[1] Xiaoming Liu. Research on Computer Basic Teaching Reform Based on Flipping Classroom [J]. IJournal of Hunan University of Science and Technology, 2016,(04):136-137.

[2] Chunxia Lan. An Empirical Study of Higher Vocational Computer Basic Course Teaching Based on Flipping Classroom [J]. Vocational Education Forum, 2015,(23):73-77.

[3] Hui Xu. Study on Teaching Reform of Computer Basics Based on Flipping Classroom Mode[J].Journal of Lanzhou University of Arts and Science (Natural Science Edition),2015,(04):115-118. 